\title{
Self-reported body weight and weight-related stigmatization experiences among young adult women - two contexts, but similar attitudes related to body image, mental self-schemas, self-esteem, and stereotypes of people with obesity
}

\author{
Eukasz Jach $^{\text {Corresp., }}$, Sonia Krystoń ${ }^{2}$ \\ 1 Institute of Psychology, Faculty of Social Sciences, University of Silesia, Katowice, Poland \\ 2 Faculty of Social Sciences, University of Silesia, Katowice, Poland \\ Corresponding Author: Łukasz Jach \\ Email address: lukasz.jach@us.edu.pl
}

Background. Weight stigma is a serious challenge because of its negative impact on human health and harmful psychological and behavioral consequences. The aim of the study was to explore and compare the relationships between self-reported body weight and weight-related stigmatization experiences and body image, mental self-image, self-esteem, and stereotypes concerning people with obesity among young adult Polish women ( $\mathrm{N}=374$; aged between 18 and 35).

Methods. The study was conducted online on a Polish sample recruited through a social network site, a website, and snowball sampling. Body mass index (BMI) was used to assign the respondents to groups with normal or excess weight. We tested whether women enrolled in the study experienced weightrelated stigmatization using two questions based on the concepts of spoiled identity and related to the obesity stigma. The Contour Drawing Rating Scale was used to study different aspects of the body image and discrepancies between them. The Self-Discrepancy Questionnaire was used to study the selfschemas associated with mental qualities. The Polish version of the Rosenberg's Self Esteem Scale was applied to determine self-esteem level. Stereotypes concerning people with obesity were studied using the semantic differential method.

Results. Although excess weight was associated with weight-related stigmatization experiences, many women reported confronting such stigmatization even though their body weight was normal according to the World Health Organization (WHO) standards. Women with excess weight and women with weightrelated stigmatization experiences were characterized by larger discrepancies between the actual body image and the ideal, reflected, and ought body image, lower self-esteem, and more negative beliefs about their mental actual and reflected self compared to women with normal weight and without weightrelated stigmatization experiences. The study participants from all groups tended to believe their actual body image to be ampler than the ideal and the ought body images. They also believed that other people perceived their mental qualities more positively than they did. The study groups were also characterized by negative stereotypes of people with obesity, although these stereotypes were more vital in women with excess weight and women who experienced weight-related stigmatization.

Conclusion. The study shows the similarity between psychological functioning of women with selfreported excess weight and those who experience weight-related stigma. The results also provide guidelines for practical actions aimed at reducing negative mental outcomes associated with not conforming to body weight standards.

PeerJ reviewing PDF | (2020:10:54731:3:0:NEW 9 Jul 2021) 
1 Self-reported body weight and weight-related stigmatization experiences

2 among young adult women - two contexts, but similar attitudes related to

3 body image, mental self-schemas, self-esteem, and stereotypes of people with

4 obesity

5

6 Łukasz Jach ${ }^{1}$, Sonia Krystoń ${ }^{2}$

7

$8{ }^{1}$ Institute of Psychology, Faculty of Social Sciences, University of Silesia, Katowice, Poland

$9 \quad{ }^{2}$ Faculty of Social Sciences, University of Silesia, Katowice, Poland

10

11

12 Corresponding Author:

13 Łukasz Jach ${ }^{1}$

14 Institute of Psychology, Faculty of Social Sciences, University of Silesia, Grażyńskiego Street

15 53, 40-126 Katowice, Poland

16 Email address: lukasz.jach@us.edu.pl 


\section{Abstract}

18 Background. Weight stigma is a serious challenge because of its negative impact on human

19 health and harmful psychological and behavioral consequences. The aim of the study was to

20 explore and compare the relationships between self-reported body weight and weight-related

21 stigmatization experiences and body image, mental self-image, self-esteem, and stereotypes

22 concerning people with obesity among young adult Polish women $(\mathrm{N}=374$; aged between 18 23 and 35).

24 Methods. The study was conducted online on a Polish sample recruited through a social network 25 site, a website, and snowball sampling. Body mass index (BMI) was used to assign the 26 respondents to groups with normal or excess weight. We tested whether women enrolled in the 27 study experienced weight-related stigmatization using two questions based on the concepts of 28 spoiled identity and related to the obesity stigma. The Contour Drawing Rating Scale was used to 29 study different aspects of the body image and discrepancies between them. The Self-Discrepancy 30 Questionnaire was used to study the self-schemas associated with mental qualities. The Polish 31 version of the Rosenberg's Self Esteem Scale was applied to determine self-esteem level.

32 Stereotypes concerning people with obesity were studied using the semantic differential method.

33 Results. Although excess weight was associated with weight-related stigmatization experiences,

34 many women reported confronting such stigmatization even though their body weight was 35 normal according to the World Health Organization (WHO) standards. Women with excess 36 weight and women with weight-related stigmatization experiences were characterized by larger

37 discrepancies between the actual body image and the ideal, reflected, and ought body image, 38 lower self-esteem, and more negative beliefs about their mental actual and reflected self 39 compared to women with normal weight and without weight-related stigmatization experiences. 
40 The study participants from all groups tended to believe their actual body image to be ampler

41 than the ideal and the ought body images. They also believed that other people perceived their

42 mental qualities more positively than they did. The study groups were also characterized by

43 negative stereotypes of people with obesity, although these stereotypes were more vital in

44 women with excess weight and women who experienced weight-related stigmatization.

45 Conclusion. The study shows the similarity between the psychological functioning of women

46 with self-reported excess weight and those who experience weight-related stigma. The results

47 also provide guidelines for practical actions aimed at reducing negative mental outcomes

48 associated with not conforming to body weight standards. 
49

50

51

52

53

54

55

56

57

58

59

60

61

62

63

64

65

66

67

68

69

70

71

\section{Introduction}

Weight-related stigma can be defined as the experience of verbal or physical abuse secondary to being overweight or obese (Wu, Berry, 2017). Stigmatization signals may come, for instance, from employers and co-workers (Watson, Levi, Lavack, 2017), scholars (Cameron, 2016), health care employees (Tomiyama et al., 2018), or family members and partners (Puhl, Bronwell, 2011; Hunger, Major, Blodorn, Miller, 2015). Weight-related stigma has a negative impact on health (O’Brien et al., 2016; Wu, Berry, 2017), psychological well-being (e.g., reduced self-esteem, anxiety, depression, eating disorders; see e.g., Kahan, Puhl, 2017; Walsh et al., 2018) or everyday functioning (e.g., maladaptive coping strategies, binge-eating or exercise avoidance; see: Hayward, Vartanian, Pinkus, 2018; Jackson, Steptoe, 2017; Wu, Berry, 2017). Stigmatization causes psychological and physiological stress, depletes self-control resources necessary to regulate healthy behavior, and increases motivation to avoid potentially discriminatory situations (Ashmore, Friedman, Reichmann, Musante, 2008; Vani, Pila, Willson, Sabiston, 2020; Hayward, Vartanian, Pinkus, 2018; Hunger, Major, Blodorn, Miller, 2015; Jackson, Steptoe, 2017). Experiencing constant stigma weakens mental and physical health and contributes to weight gain, perpetuating the source of the stigma (Puhl, Brownell, 2001, 2006). By experiencing long-term stigmatization in various social situations, individuals with excess weight may also internalize the stigma (Kahan, Puhl, 2017; Pearl, Puhl, 2018) and develop a negative body image.

The pressure exerted on individuals with excess weight is a socially acceptable form of stigmatization (Kasardo, McHugh, 2015; Myers, Rothblum; Puhl, Brownell, 2001; Puhl, Heuer, 2010), and the negative attitude is all the stronger because the stigmatized trait seems to be controllable (Crandall, Biernat, 1990; Kasardo, McHugh, 2015; Puhl, Heuer, 2010; Vartanian, 
72 2010). People with obesity are perceived as lazy, ugly, lonely, clumsy, and weak-willed

73 (Davison, Britch, 2004; Głębocka, Szarzyńska, 2005; van Leeuven, Hunt, Park, 2015). There is a

74 stereotypical erroneous belief that experiencing shame due to excess body weight stimulates the

75 individual to change their eating habits, thus bringing the desired effects (Hunger, Major,

76 Blodorn, Miller, 2015; Powell, Hendricks, 1999).

77 A concept related to the sense of lacking the desired qualities is the regulatory factor in 78 the self-discrepancy theory by Higgins $(1987,1989)$. According to this approach, the structure of 79 the human self consists of three elements. The actual self represents how individuals perceive 80 themselves; the ideal self refers to what kind of person they would like to be, while the ought self 81 refers to the qualities they think they should have to meet external expectations. Referring to the 82 theory by Goffman (1986), the reflected self can also be indicated. It is a personal conviction 83 about the traits other people attribute to the individual. Discrepancies between the schemas affect

84 how individuals treat themselves. A difference between the actual self and the ought self generates a feeling of failure to meet the standards associated with shame, self-contempt, and the desire to punish themselves. Inconsistency between the actual self and the reflected self induces problems with defining one's own identity and difficulties related to defining one's aspirations. However, a mismatch between the actual self and the ideal self is connected with a depressed mood and a feeling of self-disappointment (Bąk, 2002).

91 results are ambiguous. Longitudinal studies by Kiviruusu et al. (2016) showed that in women body weight and self-esteem were negatively related regardless of their age, but negative relations between these variables characterized middle-aged men only. Similarly, a meta-analysis by Miller and Downey (1999) showed that while the overall relationship between body weight 
95 and self-esteem was negative, this effect was more substantial for women. Self-esteem is the

96 individual's belief related to one's general value, which may be expressed in verbal declarations

97 (Rosenberg, 1965; Laguna, Lachowicz-Tabaczek, Dzwonkowska, 2007). Although it is

98 commonly believed that people with low self-esteem are convinced of their worthlessness, their

99 self-value is rather unstable. Their self-esteem is thus more malleable and susceptible to new

100 information (Wojciszke, 2011). This approach is in line with Goffman (1986), who noted that

101 stigmatized individuals displayed an ambivalent attitude toward themselves and people bearing

102 the same stigma. The related stereotypes provide the context which makes it possible to perceive

103 excess weight in terms of the overall stigma (e.g., Watson, Levi, Lavack, 2017). Stereotypes

104 have an underlying sociocultural foundation and create an environment that shapes how people

105 treat one another (Link, Phelan, 2001). The stereotyped individuals may tend to share the

106 stereotype or behave in accordance with it (Latrofa, Vaes, Cadinu, 2012). Moreover, such

107 individuals tend to stigmatize other bearers of the same stigma, depending on how visible it is

108 (Becker, Tausch, 2014).

109

110 Aims of the study and research hypotheses

111 The aim of the study was to explore and compare the relationships between self-reported

112 body weight and weight-related stigmatization experiences and body image, mental self-image,

113 self-esteem, and stereotypes concerning people with obesity among young adult women (aged

114 18-35). The above variables may be shaped in close connection with body weight and provide

115 the context for functioning in such areas of everyday life as social relations, work, education,

116 manners of relaxation, and spending free time. 
118 body weight as higher than it actually is more often than men (Chang, Christakis, 2003). They

119 are also more dissatisfied with their weight and body image (Rozin, Fallon, 1998). In women,

120 excess body weight is also related to more pronounced negative psychological consequences

121 (Magallares, Pais-Ribeiro, 2014; Miller, Downey, 1999). Focusing on the group of young adult

122 women was related to developmental, psychological, and sociocultural factors, the specificity of

123 which in each developmental period may be differently related to both the perception of body

124 weight and the studied variables (Hutchison, Leigh, Wagner, 2016).

125 Since weight stigma is based not only on the actual appearance of the body but also on

126 subjective feelings, both the self-reported BMI and weight-related stigmatization experiences

127 were considered. It was hypothesized (H1) that self-reported normal or excess weight of the

128 studied women would not coincide with their weight-related stigmatization experiences.

129 Since excess weight is considered an undesirable trait, another hypothesis (H2) was

130 formulated, i.e., women with excess weight would have lower self-esteem than women with

131 normal weight, and women experiencing weight-related stigmatization would have lower self-

132 esteem than those not experiencing such stigmatization.

133 Considering the significance of sociocultural influences for the attitude toward one's

134 body, we hypothesized (H3) that compared to women with normal weight and women not

135 experiencing weight-related stigmatization, women with excess weight and women experiencing

136 weight-related stigmatization (a) in terms of the actual body image and the mental actual self

137 would tend to perceive themselves more distinctly as "fat persons" and have a less positive

138 image of their mental traits. Additionally, (b) in terms of the ideal and ought body image, they

139 would display similar schemas related to the preferred figure. Next, (c) in terms of the reflected 
140 body image and the mental reflected self, they would tend to recognize that other people perceive

141 them as "fat persons" and as individuals with less positive mental traits. Finally, (d) they would

142 display larger discrepancies between actual body image and other aspects of the body image as

143 well as more discrepancies between the mental actual and reflected self.

144 Concerning the potential internalization of weight-related stereotypes and the occurrence

145 of lack of identification with the stigmatized group, we also hypothesized that (H4) women with

146 excess weight and women experiencing weight-related stigmatization would show a similar

147 tendency to maintain the stereotypes of people with obesity compared to women with normal

148 body weight and women not experiencing weight stigma.

149

150 Materials \& Methods

151 Participants and procedure

152 The study was conducted online on a Polish sample of female participants. The

153 participants were recruited through social network site (Facebook: profile of one of the authors

154 of the manuscript and profile Kobieta Puszysta, dedicated to women with excess weight), a

155 website (https://www.kobietaxl.pl; a Polish website dedicated to women with excess weight) and

156 snowball sampling (people who received information about the study were asked to pass it on to

157 others via the same social networking site). The criteria for inclusion in the sample were: being a

158 woman between 18 and 35 years of age, having normal or excess BMI, using the Polish

159 language, and having access to the Internet. The procedure was anonymous and voluntary. It was

160 approved by the Ethics Committee of the University of Silesia (decision number:

161 KEUS.18/04.2020). The participants were informed that the research would be related to the

162 psychological aspects of experiencing stigma and gave their informed consent to participate by 
163 going to the subsequent sections of the survey. To give the respondents a greater sense of

164 anonymity, signed consent forms to participate in the study were not collected from them.

165 However, each respondent had the opportunity to withdraw from the research procedure at any

166 time. Additionally, the participants had the opportunity to contact the study authors in case of 167 any questions or comments.

168 Four hundred seventy-five women responded. However, the data from 374 individuals 169 who met the inclusion criteria were used for further analyses. Fifty-two individuals with BMI 170 values indicating underweight, 2 individuals under 18 years of age, 45 individuals over 35 years 171 of age, and 2 respondents who did not give information about their body weight were excluded 172 from the study. No information on ethnicity was collected during the study. However, since the 173 study was conducted in the Polish language, it can be assumed that the vast majority of 174 respondents were Caucasian women from Poland or other Slavic countries where Polish is 175 relatively often used.

176 Descriptive statistics related to demographic aspects and psychological variables are 177 presented in Table 1. Due to the non-normality of the distributions of the measured continuous 178 variables, we only present the values of the medians and the lower and upper quartiles. [TABLE 1]

\section{Data collection measurements}

Body Mass Index (BMI) was used to assign the respondents to groups with self-reported

182 normal or self-reported excess weight. According to the World Health Organization (WHO),

183 normal BMI ranges from 18.50 to 24.99, BMI between 25.00 and 29.99 indicates overweight, 184 and the values of 30.00 and more indicate obesity (URL:

185 https:/www.who.int/data/gho/data/themes/topics/topic-details/GHO/ncd-risk-factors; accessed 
186 187 188 189 190 191 192 193 194 195 196 197 198 199 200 201 202 203 204 205 206 207 208

on 7 April 2021). In line with the WHO standards, BMI ranging between 18.50 and 24.99 indicated normal body weight, while higher BMI values indicated excess weight.

We used two questions, based on the concept of spoiled identity (Goffman, 1986) and concepts related to the obesity stigma (Alegría, Larsen, 2015; Davison, Birch, 2004, Hunger, Major, Blodorn, Miller, 2015) to test whether the participants experienced weight-related stigmatization. The following questions were asked: "Do you think you are fat now?"; and "Are you currently ashamed of how much you weigh?". If the participant answered affirmatively to either of these questions, she was assigned to the group with weight-related stigmatization experiences (For a discussion of the validity of the adopted method of measuring weight-related stigma experiences, see the Study limitations section.). Therefore, each participant was assigned to two categories related to (normal or excess) BMI and (the presence or absence of) weightrelated stigmatization experiences.

The Contour Drawing Rating Scale (Thompson, 2004; Wertheim, Paxton, Tilgner, 2004) was used to study different aspects of the body image and their discrepancies. The tool contains nine female figure drawings arranged on a scale from very slim to very obese. Each respondent was asked to indicate the figure showing (1) what she would like to look like (ideal body image), (2) what she looked like in her opinion (actual body image), (3) what she looked like in the opinion of others (reflected body image), (4) the type most preferred by men (ought body image according to men) and (5) the type most preferred by women (ought body image according to women).

To study the self-schemas associated with mental qualities, we used the Self-Discrepancy Questionnaire (SkRAP; see: Wojdyło, Buczny, 2011). This tool consists of twelve items referring to such positively valued traits as initiative, cleverness, creativity, wisdom, motivation, 
209 courage, diligence, prudence, strong will, orderliness, perseverance, and resourcefulness. The

210 task of the respondent was to indicate the extent to which she possessed the relevant quality

211 (mental actual self) and the extent to which the trait was seen in her by other people (mental

212 reflected self). The responses were assessed on a scale from 1 (very low level) to 10 (very high

213 level). The comparison between the overall results for the mental actual self and the mental

214 reflected self allowed the evaluation of discrepancies between them. The Cronbach's $\alpha$

215 coefficients were .87 for the mental actual self scale and .89 for the mental reflected self scale.

216 The Polish version of the Rosenberg's Self Esteem Scale (Laguna, Lachowicz-Tabaczek,

217 Dzwonkowska, 2007) was used to determine self-esteem levels. It consists of ten items related to

218 the respondents' beliefs about themselves. They refer to each item by selecting one of four

219 answers arranged on a scale from "strongly agree" to "strongly disagree". The higher the overall

220 score, the higher the respondent's self-esteem is. The Cronbach's $\alpha$ coefficient was .89 .

221 Stereotypes about individuals with obesity were studied using the semantic differential

222 method (Głębocka, Szarzyńska, 2005; Rosenberg, Navaro, 2018). The task of the respondents

223 was to indicate what they believed other people thought about individuals with obesity in relation

224 to ten opposite pairs of terms such as "lazy/hard-working", "scruffy/neat", "messy/tidy",

225 "lacking control/strong-willed", "ugly/pretty"; "stupid/smart”, "self-indulgent/disciplined",

226 "setting limits for themselves/self-restricting", "unattractive/attractive" and "quitting/persistent".

227 The respondents indicated their answers on a seven-point scale. Values 1 to 3 indicate a tendency

228 toward negative categories, while values 5 to 7 indicate a positive categorization. The overall

229 result is the average score obtained for all the items, ranging from 1 to 7 . The Cronbach's $\alpha$

230 coefficient was .88 .

231 Data analysis methodology

Peerj reviewing PDF | (2020:10:54731:3:0:NEW 9 Jul 2021) 
McNemar chi-square test to test hypothesis 1 . This test is used with matched pairs of

234

235

236

237

238

239

240

241

dichotomous measurements to check that the frequencies of certain conditions are equal. In the case of hypothesis 1, excess weight was written in rows, and having weight-related stigmatization experiences was written in columns. We planned to use two-sample comparison tests to test hypotheses 2-4. Additionally, during the analyses related to hypotheses 2 and 3 , we decided to make a series of comparisons of the results obtained by the same people on different scales; therefore we planned to use tests for matched pairs.

In order to check the possibility of using parametric tests for the planned analyses, we

initially conducted an analysis of the distributions of the residuals. Due to the numerous noticed deviations of the residuals from the normal distribution, we decided to use non-parametric tests. Due to the non-normality of distribution of the studied quantitative variables (see Table 1), we used non-parametric tests, i.e., the McNemar chi-square test, the Mann-Whitney U test (for two-sample comparisons), and the Wilcoxon signed-rank test (for matched pairs). A twosided p-value below .05 was considered statistically significant. For multiple comparisons carried out in connection with hypotheses 2 and 3, the Holm-Bonferroni correction was applied. The corrected $p$-values were calculated for all combined analyzes performed in accordance with hypotheses 2 and 3. Similarly, the corrected p-values were calculated for the combined set of additional analyzes. Rank biserial correlation coefficients and matched rank biserial correlation coefficients were used to determine the effect size.

\section{Results}

\section{H1: Self-reported body weight and experience of weight-related stigmatization}


The McNemar chi-square test was used to study the relationship between the actual body

255

256

257

258

259

260

261

262

263

264

265

266

267

268

269

270

271

272

273

274

275

276

weight and weight-related stigmatization experiences among participants. Its result showed a significant relationship between the studied variables at $\mathrm{p}<.001$. Out of 80 participants with excess weight, only $8(10.0 \%)$ did not declare weight-related stigmatization experiences.

However, of 173 participants with weight-related stigmatization experiences, the majority (101 participants; $58.4 \%$ ) had normal BMI according to the WHO standard. The obtained results supported hypothesis 1 , positing inconsistency between the self-reported weight and weightrelated stigmatization experiences. The experiences of weight-related stigmatization occurred much more frequently among the respondents than excess weight as indicated by BMI values.

\section{H2 and H3: Body image, self-esteem, and mental self-schemas in the context of self-}

\section{reported weight and weight-related stigmatization experiences}

The groups with different BMI values and weight-related stigmatization experiences were compared in terms of body image, self-esteem, and self-schemas related to mental traits. The relevant information is given in Table 2. Due to multiple comparisons, the Holm-Bonferroni correction was used (the number of planned comparisons was 13 for groups with different BMI and 13 for groups with different weight-related stigmatization experiences).

\section{[TABLE 2]}

Significant differences between the groups were similar, regardless of whether they were distinguished due to self-reported body weight or weight-related stigmatization experiences. As far as the actual body image was concerned, the respondents with excess BMI indicated ampler figures compared to respondents with normal weight. Also, the respondents with weight-related stigmatization experiences indicated ampler figures compared to respondents without such experiences. Significant differences were also observed between women who differed in terms of 
277 BMI regarding the ideal body image, i.e., women with normal weight indicated slimmer figures 278 as desirable. Regardless of the criterion, significant differences were found between the groups 279 regarding the reflected body image, which indicated ampler figures by respondents with excess 280 weight and respondents with weight-related stigmatization experiences. No differences were 281 found between the groups in terms of the aspects of the ought body image, which indicated the 282 similarity of figures that were considered preferred by other women and men. The discrepancies between the actual body image and other aspects of body image were 284 also analyzed. They became more prominent in women with excess weight than in those with 285 normal weight and in women with weight-related stigmatization experiences than in those without such experiences.

The groups also differed in terms of mental aspects. The respondents without weight288 related stigma experiences had higher self-esteem and a more positive image of mental traits compared to those with weight-related stigma experiences. However, the group with normal BMI 290 values showed only a higher level of the mental actual self than the group with excess BMI. No significant differences were found in terms of the discrepancy between the mental actual self and the mental reflected self between the groups. experiences reported lower self-esteem than women without such experiences. However, the results showed no significant differences in self-esteem in women with normal and excess BMI.

Hypothesis 3 was also only partly confirmed. Regardless of the criterion, women with excess weight and those with weight-related stigma experiences indicated ampler figures corresponding to their actual body image, and they had a less positive image of their mental traits. In most aspects, they were also characterized by larger discrepancies between the actual 
300 body image and other aspects of the body image. A result that diverged from the hypothesis was

301 the difference in terms of the body figure considered ideal. Women with excess BMI values

302 preferred slightly ampler figures than women with normal weight. Another result that was

303 inconsistent with the hypothesis was the comparable level of numerical discrepancies in the

304 participants between the mental aspects of the actual self and the reflected self. However,

305 positive values of rank-biserial correlation coefficients indicated a larger discrepancy between

306 the actual body image and the reflected body image, characterizing women with normal BMI

307 and women without weight-related stigmatization experiences rather than women with excess

308 BMI and with weight-related stigmatization experiences.

309 Additionally, we tested whether significant differences between the actual self and other

310 self-schema elements occurred within subgroups of the participants. Wilcoxon signed-rank tests

311 were conducted for this purpose. Due to multiple comparisons, the Holm-Bonferroni correction

312 was used: the number of planned comparisons was five within each of the four groups. The

313 results are shown in Table 3.

314

315

316

317

318

319

320

321

322

[TABLE 3]

In each group, significant differences occurred between the actual body image and its other aspects. The participants displayed their desire to have a slimmer figure and believed that their body type was ampler than both male and female standards concerning the most preferred body shape. When the participants compared their figures with the way other people perceived them, they indicated that their actual body image was almost in every case ampler than the reflected body image, excluding the group with excess BMI values. However, the comparison of the measured mental aspects of self showed that all groups of women were characterized by a more positive reflected self than actual self.

Peerj reviewing PDF | (2020:10:54731:3:0:NEW 9 Jul 2021) 
323

324

325

326

327

328

329

330

331

332

333

334

335

336

337

338

339

340

341

342

343

344

345

\section{9}

H4: Self-reported BMI, weight-related stigmatization experiences, and the stereotype of a person with obesity

We hypothesized that women from different groups would demonstrate a similar way of perceiving people with obesity (H4). However, the Mann-Whitney U test showed that women with excess BMI values had a more negative stereotype of people with obesity than women with normal BMI: this difference was significant at $\mathrm{p}<.001$, and the rank-biserial correlation coefficient was .330; median (interquartile range) in the group with normal BMI was 2.40 (1.00) and in the group with excess BMI was $2.00(.85)$. Similarly, women with weight-related stigmatization experiences were characterized by a more negative image of people with obesity than respondents who did not declare such experiences: this difference was significant at $\mathrm{p}<$ .001 and the rank-biserial correlation coefficient was .227; median (interquartile range) in the group without weight-related stigmatization experiences was $2.40(.90)$, and in the group with weight-related stigmatization experiences was $2.20(.90)$. The median values related to the stereotype were in the lower range of the scale, which indicates negative attitudes toward people with clearly higher-than-normative weight in each study group.

\section{Discussion}

\section{Relations between self-reported BMI and weight-related stigma experiences}

The analyses performed demonstrated that weight-related stigma experiences generally co-occurred with excess BMI. However, the number of respondents who experienced weightrelated stigma was much larger than those who had a BMI above the norm. It suggests that the psychological significance of weight stigma diverges significantly from what above-normative 
346 weight means in an objective, medical sense (cf. Cooper, Deepak, Grocutt, Bailey, 2007). This

347 discrepancy creates the risk that negative psychological phenomena accompanying the

348 confrontation with the sociocultural context of weight stigma may accompany women with

349 excess weight and a significant number of women who only think that they are above the normal 350 range (Romano, Haynes, Robinson, 2018). Currently, on the one hand, body weight categories

351 are used as indicators of other traits (e.g., mental attributes). On the other hand, they determine

352 the scope of activities which the individual can undertake without feeling ashamed or

353 mismatched (van Leeuven, Hunt, Park, 2015). However, the frequency of weight-related

354 stigmatization experiences among women whose weight is normal suggests that weight-related

355 categories can serve as a social control tool (Bartky, 1997; Rail, Holmes, Murray, 2010). Its

356 effectiveness may be all the greater because while other negative stereotypes (e.g., racial or

357 sexual) are currently clearly rejected, there is social consent for the negative treatment of

358 individuals with excess weight (Brewis, SturtzSreetharan, Wutich, 2018; Charlesworth, Banaji, 359 2019).

360 Body image, mental self-schemas, and self-esteem

361 Significant differences noted in the actual and reflected body images did not seem to be 362 surprising. Women with excess BMI values perceived their figure as ampler and believed that 363 this was how other people perceived them (see Table 2). More interesting results were obtained 364 as regards the ideal aspect of the body image. No significant differences were observed in this 365 respect between women with and without weight-related stigmatization experiences. It supports 366 the thesis that culturally created models of an ideal figure exist in today's world and are 367 assimilated by most people regardless of their actual appearance (Swami, 2015), especially since 368 the differences between the actual and ideal body image were also noted in other studies 
369 (Crossley, Cornelissen, Tovée, 2012; Rozin, Fallon, 1988). From a different perspective, women

370 with excess BMI values indicated a slightly ampler figure contour as ideal compared to

371 respondents with normal BMI. However, both groups of women agreed on what their bodies

372 should look like to fit in with the preferences of both men and women. These results also

373 supported the notion that universal models of attractiveness were internalized by the respondents,

374 who compared their actual figure to them (Engeln-Maddox, 2005).

375

Interestingly, on the one hand, the figures indicated as preferred by men were slightly

376

ampler than those which in the opinion of the respondents were preferred by other women. On

377 the other hand, they were more similar to the figure types, which the respondents indicated as

378 ideal for themselves. It suggests that the participants were more interested in conforming to the

379 canons of beauty formulated within the framework of the other gender. An additional analysis

380 performed in this context showed that according to the respondents, the standards of appearance

381 imposed by other women were even more stringent than male standards (in Wilcoxon signed-

382 rank test, the $\mathrm{p}$-value was less than .001 ; matched rank biserial correlation $=.807$ ). Therefore, it

383 seems that other women were seen as more severe "judges" than men in terms of physical

384 appearance (cf. Evans, 2003). From an evolutionary perspective, this may mean that physical

385 appearance is a signal of attractiveness to potential partners and a tool used in the intra-gender

386 competition for a social position (Fink, Klappauf, Brewer, Shackelford, 2014). However,

387 Crossley, Cornelissen, and Tovée (2012) indicated that male and female ideal images of the

388 female body were compatible. Thus, according to men and women, the differences related to

389 ought body images indicated by the participants may not be reflected in reality.

390 In most cases, higher numerical differences occurred between the figures indicated as

391 those reflecting the actual body image and other aspects of the body image among women with 
392 excess BMI and women who experienced weight-related stigmatization. An exception was found

393 in differences between the actual and the reflected body images, which were statistically

394 significant but not pronounced in numerical terms based on median and interquartile range

395 values. Thus, the discrepancies between the actual self and reflected self were most similar in the 396 studied groups among all measured discrepancies.

397 The results related to the images of the mental actual self and the mental reflected self 398 overlapped with those connected with body image aspects. However, after applying the Holm399 Bonferroni correction, there were more significant differences in relation to weight-related 400 stigmatization experiences. The respondents without weight-related stigmatization experiences 401 had a more positive image of the mental actual self than those who declared such experiences. 402 These women also demonstrated a higher conviction that their image was more positive in the 403 eyes of other people. Further analyses showed that all the respondents had a more positive image 404 of the mental reflected self than the mental actual self, and the intergroup discrepancies between 405 these two images were insignificant.

Women with normal BMI and without weight-related stigmatization experiences were 407 also characterized by a higher level of self-esteem than women with high BMI values and those 408 who declared such experiences. The obtained results are in line with the previous reports on the 409 relationship between body weight and self-esteem in women (e.g., Miller, Downey, 1999;

410 Kiviruusu et al., 2016). However, the difference related to BMI values was insignificant after 411 applying the Holm-Bonferroni correction. It suggests that how the respondents perceived their 412 value might have been more related to their attitudes toward their bodies rather than what they 413 looked like (Lennon, Rudd, Sloan, Kim, 1999; Shahyad, Pakdaman, Shokri, 2015). 
417 preferred body shape as well as the body type preferred by men and other women. The fact that

418 even women with normal weight and without weight-related stigmatization experiences declared 419 significant discrepancies between their actual figure and the ideal and ought canons related to it 420 suggests how common dissatisfaction with one's appearance is (Ghaznawi, Taylor, 2015;

421 Homan, McHugh, Wells, Watson, King, 2012).

\section{2}

423

424

425

426

\section{The stereotype of the person with obesity}

Given that the body is an element of culture that regulates the ways of using it and provides interpretations of its appearance (Adelman, Ruggi, 2016), we predicted that regardless of their body weight and weight-related stigma experiences, the respondents would have similar beliefs about people with excess weight. The study results revealed unfavorable stereotypes of people with obesity in the groups of respondents. However, respondents with high BMI and with weight-related stigma experiences expressed even less positive opinions. This result indicates the wide extent of sociocultural stigmatization of people whose weight is above the normal range (see Vartanian, 2010). Individuals with normal BMI and without weight-related stigmatization experiences convinced of the negative traits of people with obesity may feel satisfaction from being better than the above-mentioned group and may pursue their daily activities with a sense of anxiety that they might potentially contribute to being classified in the group with undesirable characteristics. In turn, individuals with excess BMI and weight-related stigma experiences who share the stereotypes about themselves may contribute to their consolidation and may not feel motivated to change them for two reasons. The first one is related to the hope of leaving the 
437 stereotypical group and becoming a member of the normative group (Becker, Tausch, 2014). The

438 second one is connected with the gradation of the physical problem of excess body weight.

439 Women with excess weight may perceive those who diverge from the norm even more as having 440 a higher intensity of negative traits. Thus, paradoxically, the stereotypical perception of people

441 with obesity may help them maintain higher self-esteem, as they feel that others are even worse

442 than them (Brown, Novick, Lord, Richards, 1992).

\section{Study limitations}

The study sought to consider factors that may be significant for the functioning of women with excess weight. Particular attention was focused on making sure that the respondents would

447 constitute a homogeneous group of young adults to minimize the risk of physical differences

448 between them related to developmental factors (e.g., hormonal factors). Care was also taken to 449 exclude individuals with excessively low body weight. Moreover, the complexity of normative 450 aspects of weight was considered, including its actual aspect (normative criteria of BMI 451 according to WHO) and the subjective experiences of weight-related stigmatization.

452 However, we found factors that could affect the obtained results. Although BMI is 453 commonly used to determine whether an individual's weight is within the normal range, it also

454 has certain disadvantages. One of them is the possibility of obtaining higher results by 455 individuals who perform physical exercise or athletic individuals whose muscular figures can be 456 classified in the same category as those of people with overweight (Nevill et al., 2010). Another 457 disadvantage was related to applying a general category of excess weight in terms of respondents 458 with BMI values $\geqslant 25.00$, although a distinction between people with overweight (BMI between 45925.00 and 29.99) and people with obesity $(\mathrm{BMI}>30.00)$ would have been more specific here. 
460 We decided to adopt a general cut-off point to avoid excessive fragmentation of the groups. In 461 the sample, women with excess BMI values accounted for $21.4 \%$ of the respondents, $14.2 \%$ of 462 whom had BMI indicating overweight, and 7.2\% had BMI indicating obesity. However, the 463 analyses were conducted to test whether similar conclusions to those presented in the paper could 464 be drawn if BMI could be treated as a trichotomous variable (as an indicator of normal weight, 465 overweight, and obesity). The analyses are given in Table S1 (see Supplementary information). 466 The obtained results are similar to those regarding hypotheses $2-4$. Nevertheless, differentiation 467 between subgroups exceeding the normative weight is recommended on a larger sample.

468 Studies also showed that BMI calculation based on declarations could lead to 469 underestimating body weight and overestimating height (Gorber, Tremblay, Moher, Gorber, 470 2007; Maukonen, Satu, Tolonen, 2018). This effect may have been partly responsible for the 471 study discrepancy between the size of groups with excess weight and weight-related 472 stigmatization experiences. In turn, some research showed that study participants reported their 473 weight fairly accurately (Luo et al., 2019; Stunkard, Albaum, 1981; for young adults, see: Olfert 474 et al., 2018).

475 As the study was conducted on a sample using the snowball method, questions may arise 476 regarding its representativeness and the possibility of generalizing the obtained results. The 477 applied research methodology allows us to consider the obtained results preliminary. Further 478 studies on more representative samples are warranted. From a different perspective, the 479 percentages of women with normal weight and excess weight who participated in the study were 480 very similar to those among young women in the general Polish population. According to the 481 Statistics Poland data (2014; URL: https://stat.gov.pl/en/topics/health/health/percentage-of482 persons-aged-15-years-and-more-by-body-mass-index-bmi,11,1.html; accessed on 7 April 2021), 
483 among Polish women aged $20-29,73.2 \%$ of people had normal BMI, and $17.8 \%$ had excess 484 BMI, whereas among Polish women aged $30-39,64.3 \%$ of people had normal weight and $31.5 \%$ 485 had excess BMI. These percentages are comparable to those in the study $(78.6 \%$ and $21.4 \%$, 486 respectively), especially if we consider that the general population also includes people with low 487 BMI, and the difference in proportions would even decrease if they were not considered.

Doubts may also arise regarding the mental aspects of the actual self and the reflected self 489 based on a single generalized value, constituting the result of the measurement using the Self Discrepancy Scale (SkRAP). This tool allows the comparison of responses with regard to each 491 item. However, this would have led to the replacement of multi-item scales with good internal consistency with a set of single-item scales for which it would not have been possible to establish the reliability level. There are also limitations related to the determination of body image aspects based on the Contour Drawing Rating Scale. According to Crossley, Cornelissen, and Tovée (2012), methods based on a limited set of alternatives presented in 2D may have low validity concerning actual preferences related to body image. On the other hand, the advantage of the above scale is that it can be used in large sample surveys such as the one in this paper.

An important issue not addressed in the study is the interactions between self-reported BMI and weight-related stigmatization experiences. Such analyses were not performed due to the disproportions of participants that would have been distinguished in the $2 \times 2$ pattern. The group 501 of women with excess BMI values who did not declare weight-related stigmatization experiences 502 would have been particularly too small (only eight respondents). 
506 concept of stigmatization, considering social and personal internalization aspects (Goffman, 507 1986; Kahan, Puhl, 2017). The question "Do you think you are fat now?" was considered a

508 weight-related stigmatization experiences indicator since it refers to the introjected negative 509 category related to body weight. In Polish, there are many euphemisms and synonyms for excess 510 weight (cf. Roszak, 2013), and the meaning of the adjective "fat" is similar to English "thick" 511 and considered rather insulting. Some studies also show that people described as "fat" were 512 perceived more negatively than people described with other weight descriptors (Brochu, Esses,

513 2011; Smith, Schmoll, Konik, Oberlander, 2007) or without any weight descriptors (Smith,

514 Schmoll, Konik, Oberlander, 2007). Using of the adjective "fat" as a self-descriptor seems to be

515 consistent with Goffman's concept of "spoiled identity" (1986), which was the theoretical

516 context of the presented study. However, within the fat acceptance movement, attempts are 517 currently being made to make the adjective "fat" a neutral descriptor (Meadows, Daníelsdóttir, 518 2016).

The question "Are you currently ashamed of how much you weigh?" was considered a

520

521

522

523

524

525

526

527

528

weight-related stigmatization experiences indicator because it literally refers to the embarrassing aspects of weight-related stigma. The question "Are you currently ashamed of how much you weigh?" may seem problematic here because someone may be ashamed not only of too high body weight but also of too low body weight. However, the probability of a significant distortion of the study results due to the above factor was minimal. Of all respondents, only $11(2.9 \%)$ participants declared that their ideal body image was ampler than the actual body image. Among them, only one person confirmed embarrassment due to her figure and declared no feeling of "being fat" and no social signals indicating it. Similar doubts may arise because some excess weight people might perceive themselves as "fat" but not be ashamed of it, which could be an 
529 indicator of "fat and proud” self-schema (Meadows, Daníelsdóttir, 2016; Casadó-Marín, Gracia-

530 Arnaiz, 2020). However, only seven of the 80 participants with excess weight responded to that

531 pattern in our sample. Moreover, the additional analyses performed using the Mann-Whitney U

532 test, and the Holm-Bonferroni correction showed no statistically significant differences between

533 these 7 participants and the remaining 73 participants with excess BMI in terms of measured

534 aspects related to body image, mental self, self-esteem, and obese people stereotype. However,

535 future studies with a similar methodology should focus in a less ambiguous manner on weight-

536 related stigmatization experiences.

537

538 Conclusions

539

Regardless of BMI, any woman may experience weight-related stigmatization, which is

540 related to failure to meet the standards of attractiveness (Krzemionka-Brózda, 2010, Leksy,

541 2013; Swami, 2015). The study results show the similarity between the psychological

542 functioning of women with self-reported excess BMI and those who feel that their weight was

543 above the normal range. The results also provide guidelines for practical actions aimed at

544 reducing negative mental states associated with not conforming to the canons of beauty. Firstly,

545 the disproportion between the number of respondents with excess BMI and the number of

546 women declaring weight-related stigmatization experiences indicates that weight stigma is only

547 partly based on objective factors. Therefore, mitigation of its impact requires applying measures

548 aimed at changes in psychological, social, and cultural areas (Brewis, SturtzSreetharan, Wutich, 549 2018).

550 Secondly, the discrepancies revealed in each group between the actual body image and its

551 other aspects lead to the conclusion that dissatisfaction with the body shape is a common 
552 phenomenon, regardless of the actual compliance with the bodyweight criteria. The above should

553 be indicated to individuals who struggle with excess body weight, who may experience

554 disappointment when expectations clash with reality and weaken their motivation to pursue

555 healthier habits (Garner, Wooley, 1991). From a different perspective, a longitudinal study by

556 Rancourt et al. (2017) showed that weight misperception among young people with excess

557 weight did not necessarily lead to further weight gain. However, the persistence of the positive

558 effects of weight misperception may be difficult in the contemporary cultural context in which

559 constant attention is paid to the importance of a slim figure.

560 Thirdly, the results show the importance related to the opinions of others in the context of

561 body normativity. The respondents unanimously declared that the ought body standards were

562 more stringent from the point of view of other women than the corresponding standards

563 attributed to men. The results suggest that women feel a stronger sense of a mismatch between

564 the models articulated within their gender. This aspect should be considered when developing

565 strategies to eliminate the harmful effects of weight stigma. To replace narratives depicting men

566 and women as opposing forces fighting for different standards, it might be appropriate to

567 introduce communication showing that it is in the interest of all women to change the perception

568 of the body shape, regardless of the size they wear (see: Webb, Wood-Barcalow, Tylka, 2015).

569 From a different perspective, in future research, aspects of the perceived body image could be

570 measured in a more controlled way if the respondents were asked to indicate their sexual

571 orientation and to indicate what body image in their opinion is ought in specific spheres of

572 everyday life (e.g., sexual, work-related or social).

573

574 References 
575 Adelman, M., Ruggi, L. (2016). The sociology of body. Current Sociology, 64, 907-930.

576 Alegría, C.A., Larsen, B. (2015). “That's who I am: A fat person in a thin body”: Weight loss,

577 negative self-evaluation, and mitigating strategies following weight loss surgery. Journal of the 578 American Association of Nurse Practitioners, 27(3), 137-144.

579 Ashmore, J., Friedman, K, Reichmann, S, Musante, G. (2008). Weight-based stigmatization, 580 psychological distress, \& binge eating behavior among obese treatment-seeking adults. Eating 581 Behaviors. 9, 203-209.

582 Bartky, S.L. (1997). Foucault, Femininity and the Modernization of Patriarchal Power. In: K.

583 Conboy, N. Medina. S. Stanbury S. (eds.), Writing on the body: Female embodiment and 584 feminist theory (129-154). New York: Columbia University Press.

585 Bąk, W. (2002). E. Tory Higginsa teoria rozbieżności ja [E. Tory Higgins's theory of the "self” 586 discrepancy]. Przegląd Psychologiczny, 45(1), 39-55.

587 Becker, J.C., Tausch, N. (2014). Self and Identity When Group Memberships are Negative: The 588 Concept, Measurement, and Behavioral Implications of Psychological Disidentification. Self and 589 Identity, 13(3), 294-321.

590 Brewis, A., SturtzSreetharan, C., Wutich, A. (2018). Obesity stigma as a globalizing health 591 challenge. Globalization and Health, 14:20, 1-6.

592 Brochu, P.M., Esses, V.M. (2011). What's in a name? The effects of the labels "fat" versus 593 “overweight” on weight bias. Journal of Applied Social Psychology, 41(8), 1981-2008. DOI: $594 \quad 10.1111 / \mathrm{j} .1559-1816.2011 .00786 . x$

595 Brown, J. D., Novick, N. J., Lord, K. A., Richards, J. M. (1992). When Gulliver travels: Social 596 context, psychological closeness, and self-appraisals. Journal of Personality and 597 Social Psychology, 62, 717-727. DOI: 10.1037/0022-3514.62.5.717. 
598 Cameron, E. (2016). Challenging "Size Matters" Messages: An Exploration of the Experiences 599 of Critical Obesity Scholars in Higher Education. Canadian Journal of Higher Education, 46, $600 \quad 111-126$.

601 Casadó-Marín, L., Gracia-Arnaiz, M. (2020). "I'm fat and proud of it”: Body size diversity and 602 fat acceptance activism in Spain. Fat Studies, 9(1), 51-70, DOI:

$603 \quad 10.1080 / 21604851.2019 .1648994$

604 Chang, V.W., Christakis, N.A. (2003). Self-perception of weight appropriateness in the United 605 States. American Journal of Preventive Medicine, 24(4), 332-339. DOI: 10.1016/s0749$606 \quad 3797(03) 00020-5$

607 Charlesworth, T.E.S., Banaji, M.R. (2019). Patterns of Implicit and Explicit Attitudes: I. Long608 Term Change and Stability From 2007 to 2016. Psychological Science, 30(2), 174-192.

609 Cooper, M., Deepak, K., Grocutt, E., Bailey, E. (2007). The experience of 'feeling fat' in women 610 with anorexia nervosa, dieting and non-dieting women: An exploratory study. European Eating 611 Disorders Review, 15, 366-372. DOI: 10.1002/erv.785.

612 Crandall, C., Biernat, M. (1990). The ideology of anti-fat attitudes. Journal of Applied Social 613 Psychology, 20, 227-243

614 Crossley, K.L., Cornelissen, P.L., Tovée, M.J. (2012). What Is an Attractive Body? Using an 615 Interactive 3D Program to Create the Ideal Body for You and Your Partner. PLoS ONE, 7(11), 616 e50601. DOI: 10.1371/journal.pone.0050601.

617 Davison, K.K., Birch, L.L. (2004). Predictors of fat stereotypes among 9-years-old girls and their 618 parents. Obesity Research, 12(1), 86-94.

619 Engeln-Maddox, R. (2005). Cognitive responses to idealized media images of women: The 620 relationship of social comparison and critical processing to body image disturbance in college 
621 women. Journal of Social and Clinical Psychology, 24, 1114-1138. DOI:

$62210.1521 /$ jscp.2005.24.8.1114.

623 Etilé, F. (2007). Social norms, ideal body weight and food attitudes. Health Economics, 16(9), $624945-966$.

625 Evans, P. C. (2003). "If Only I were Thin Like Her, Maybe I Could be Happy Like Her": The 626 Self-Implications of Associating a Thin Female Ideal with Life Success. Psychology of Women 627 Quarterly, 27, 209-214. DOI: 10.1111/1471-6402.00100.

628 Fink, B., Klappauf, D., Brewer, G., Shackleford, T.K. (2014). Female physical characteristics 629 and intra-sexual competition in women. Personality and Individual Differences, 58, 138-141.

630 Garner, D.M., Wooley, S.C. (1991). Confronting the failure of behavioral and dietary treatments 631 for obesity. Clinical Psychology Review, 11(6), 729-780. DOI: 10.1016/0272-7358(91)90128-H.

632 Ghaznavi, J., Taylor, L.D. (2015). Bones, body parts, and sex appeal: An analysis of 633 \#thinspiration images on popular social media. Body Image, 14, 54-61. DOI:

634 10.1016/j.bodyim.2015.03.006.

635 Głębocka, A., Szarzyńska, M. (2005). Stereotypy dotyczące osób otyłych a jakość życia ludzi w 636 starszym wieku [Sterotypes of obesity and quality of life among the edlerly]. Gerontologia 637 Polska, 13(4), 260-265.

638 Goffman, E. (1986). Stigma: Notes on the Management of Spoiled Identity. New York: 639 Touchstone.

640 Gorber, S.C., Tremblay, M., Moher, D., Gorber, B.(2007). A comparison of direct vs self-report 641 measures for assessing height, weight and body mass index: a systematic review.

642 Obesity Reviews, 8, 307-326. 
643 Hayward, L. E., Vartanian, L. R., \& Pinkus, R. T. (2018). Weight stigma predicts poorer

644 psychological well-being through internalized weight bias and maladaptive coping responses.

645 Obesity, 26, 755-761.

646 Higgins, E.T. (1987). Self-Discrepancy: A Theory of Realting Self and Affect. Psychological

647 Review. 94, 319-340.

648 Higgins, E.T. (1989). Self-discrepancy theory: What patterns of self-beliefs cause people to 649 suffer? Advances in Experimental Social Psychology, 22, 93-136.

650 Homan, K., McHugh, E., Wells, D., Watson, C., King, C. (2012). The effect of viewing ultra-fit 651 images on college women's body dissatisfaction. Body Image, 9, 50-56. DOI:

652 10.1016/j.bodyim.2011.07.006.

653 Hunger, J.M., Major, B., Blodorn, A., Miller, C.T. (2015). Weighed Down by Stigma: How

654 Weight-Based Social Identity Threat Contributes to Weight Gain and Poor Health. Social and

655 Personality Psychology Compass, 9, 255-268.

656 Hutchison, B., Leigh, K.T., Wagner, H.H. (2016). Young adulthood: Emotional and social

657 development. In D. Capuzzi, M. D. Stauffer (Eds.), Human growth and development across the

658 lifespan: Applications for counselors (p. 415-442). John Wiley \& Sons, Inc.

659 Jackson, S.E., Steptoe, A. (2017). Association between perceived weight discrimination and 660 physical activity: a population-based study among English middle-aged and older adults. $B M J$ 661 open, 7(3), e014592.

662 Kahan, S, Puhl, R.M. (2017). The damaging effects of weight bias internalization. Obesity, 25, $663280-281$.

664 Kasardo, A.E., McHugh, M.C. (2015). From fat shaming to size acceptance: Challenging the 665 medical management of fat women. In M. C. McHugh, J.C. Chrisler (Eds.), The wrong 
666 prescription for women: How medicine and media create a "need" for treatments, drugs, and 667 surgery (pp. 179-201). Praeger/ABC-CLIO.

668 Kiviruusu, O., Konttinen, H., Huurre, T., Aro, H., Marttunen, M., Haukkala, A. (2016). Self669 esteem and Body Mass Index from Adolescence to Mid-adulthood. A 26-year Follow670 up. International Journal of Behavioral Medicine, 23(3), 355-363. DOI: 10.1007/s12529-015$671 \quad 9529-4$

672 Latner, J.D., Ebneter, D.S., O’Brien, K.S. (2012). Residual obesity stigma: An experimental 673 investigation of bias against obese and lean targets differing in weight-loss history. Obesity, 674 20(10), 2035-2038.

675 Latrofa, M., Vaes, J., Cadinu, M. (2012). Self-Stereotyping: The Central Role of an Ingroup 676 Threatening Identity. The Journal of Social Psychology, 152, 92-111.

677 Leksy, K. (2013). Nadmierna masa ciała - konteksty psychospołeczne i pedagogiczno678 edukacyjne [Being overweight - psycho-social and pedagogical-educational contexts].

679 Katowice: Wydawnictwo Uniwersytetu Śląskiego.

680 Lennon, S., Rudd, N., Sloan, B., Kim, J.(1999). Attitudes Toward Gender Roles, Self-esteem, 681 and Body Image: Application of a Model. Clothing and Textiles Research Journal. 17 191-202. 682 DOI: $10.1177 / 0887302 X 9901700403$.

683 Link, B.G., Phelan, J.C. (2001). Conceptualizing Stigma. Annual Review of Sociology, 27, 363684385.

685 Luo, J., Thomson, C.A., Hendryx, M., Tinker, L.F., Manson, J.E., Li, Y., Nelson, D.A., Vitolins, 686 M.Z., Seguin, R.A., Eaton, C.B., Wactawski-Wende, J., Margolis, K.L. (2019). Accuracy of self687 reported weight in the Women's Health Initiative. Public Health Nutrition, 22(6), 1019-1028. 688 DOI: 10.1017/S1368980018003002. 
689 Łaguna, M., Lachowicz-Tabaczek, K., Dzwonkowska, I. (2007). Skala samooceny SES Morrisa 690 Rosenberga - polska adaptacja metody [The Rosenberg Self-Esteem Scale: Polish adaptation of 691 the scale]. Psychologia Społeczna, 2, 164-176.

692 Magallares, A., Pais-Ribeiro, J.L. (2014). Mental Health and Obesity: A Meta-Analysis. Applied 693 Research Quality Life, 9, 295-308. DOI: 10.1007/s11482-013-9226-x

694 Maukonen, M., Männistö, S., Tolonen, H. (2018). A comparison of measured versus self695 reported anthropometrics for assessing obesity in adults: a literature review. Scandinavian 696 Journal of Public Health, 46, 565-579.

697 Meadows, A. Daníelsdóttir, S. (2016). What's in a Word? On Weight Stigma and Terminology. 698 Frontiers in Psychology,7:1527. DOI: 10.3389/fpsyg.2016.01527

699 Miller, C.T., Downey, K.T. (1999). A Meta-Analysis of Heavyweight and Self-Esteem. 700 Personality and Social Psychology Review, 3(1), 68-84. DOI: 10.1207/s15327957pspr0301_4.

701 Myers, A., Rothblum, E. (2010). Coping with prejudice and discrimination based on weight. In J. 702 L. Chin (Ed.), The psychology of prejudice and discrimination: A revised and condensed edition 703 (187-197). Santa Barbara: Praeger.

704 Nevill, A., Winter, E., Ingham, S., Watts, A., Metsios, G. Stewart, A. (2010). Adjusting athletes’ 705 body mass index to better reflect adiposity in epidemiological research. Journal of Sports 706 Sciences, 28, 1009-1016.

707 O’Brien, K., Latner, J., Puhl, R., Vartanian, L., Giles, C., Griva, K., Carter, A. (2016). The 708 relationship between weight stigma and eating behavior is explained by weight bias 709 internalization and psychological distress. Appetite, 102, 70-76.

710 Olfert, M.D., Barr, M.L., Charlier, C.M., Famodu, O.A., Zhou, W., Mathews, A.E., Byrd711 Bredbenner, C., Colby, S.E. (2018). Self-Reported vs. Measured Height, Weight, and BMI in 
712 Young Adults. International Journal of Environmental. Research and Public Health, 15, 2216.

713 DOI: 10.3390/ijerph15102216

714 Pearl, R.L., Puhl, R.M.(2016). The distinct effects of internalizing weight bias: An experimental 715 study. Body Image, 17, 38-42.

716 Powell, M.R., Hendricks, B. (1999). Body schema, gender, and other correlates in nonclinical

717 populations. Genetic, Social, and General Psychology Monographs, 125(4), 333-412.

718 Puhl, R.M., Brownell, K.D. (2001). Bias, discrimination, and obesity. Obesity Research, 9, 788719805.

720 Puhl, R.M., Brownell, K.D. (2006). Confronting and coping with weight stigma: an investigation

721 of overweight and obese adults. Obesity, 14, 1802-1815.

722 Puhl, R.M., Heuer, C.A. (2010). Obesity stigma: important considerations for public health.

723 American Journal of Public Health. 100, 1019-1028.

724 Puhl, R.M., Luedicke, J. (2012). Weight-based victimization among adolescents in the school 725 setting: emotional reactions and coping behaviors. Journal of Youth and Adolescence, 41, 27-40.

726 Rail, G., Holmes, D., Murray, S. (2010) The politics of evidence on 'domestic terrorists':

727 Obesity discourses and their effects. Social Theory \& Health, 8, 259-279. DOI:

728 10.1057/sth.2009.10.

729 Rancourt, D., Thurston, I. B., Sonneville, K. R., Milliren, C. E., Richmond, T. K. (2017).

730 Longitudinal impact of weight misperception and intent to change weight on body mass index of 731 adolescents and young adults with overweight or obesity. Eating behaviors, 27, 7-13. DOI:

732 10.1016/j.eatbeh.2017.08.002

733 Romano, E., Haynes, A., Robinson, E. (2018). Weight Perception, Weight Stigma Concerns, and 734 Overeating. Obesity (Silver Spring, Md.), 26, 1365-1371. DOI: 10.1002/oby.22224. 
735 Rosenberg, B.D. Navaro, A.M. (2018). Semantic Differential Scaling. In: B.B. Frey, The SAGE

736 Encyclopedia of Educational Research, Measurement, and Evaluation (pp. 1504-1507).

737 Thousand Oaks: SAGE Publications Inc.

738 Rosenberg, M. (1965). Society and adolescent self-image. New York: Princeton University 739 Press.

740 Roszak, M. (2013). Grubość i chudość w polszczyźnie [Thickness and thinness in the Polish 741 Language].Annales Universitatis Paedagogicae Cracoviensis. Studia Linguistica, VIII, $265-275$.

742 Rozin, P., Fallon, A. (1988). Body image, attitudes to weight, and misperceptions of figure

743 preferences of the opposite sex: a comparison of men and women in two generations. Journal of

744 Abnormal Psychology, 97(3), 342-345. DOI: 10.1037//0021-843x.97.3.342.

745 Schwartz M.B., Brownell K.D. (2002). Obesity and body image, In: T.F. Cash, T. Pruzinsky

746 (eds.), Body image: a handbook of theory, research, and clinical practice (2091-2209). New

747 York: Guilford Press

748 Shahyad, S., Pakdaman, S., Shokri, O.(2015). Prediction of Body Image Dissatisfaction from

749 Self-esteem, Thin-ideal Internalization and Appearance-related Social Comparison. International

750 Journal of Travel Medicine and Global Health, 3, 59-63. DOI: 10.20286/ijtmgh-030299.

751 Sikorski, C., Spahlholz, J., Hartlev, M., Riedel-Heller, S.G. (2016). Weight-based

752 discrimination: an ubiquitary phenomenon?. International Journal of Obesity, 40, 333-337.

753 Smith, C.A., Schmoll, K., Konik, J., Oberlander, S. (2007). Carrying weight for the world:

754 Influence of weight descriptors on judgments of large-sized women. Journal of Applied Social

755 Psychology, 37, 989-1006. DOI: 10.1111/j.1559-1816.2007.00196.x

756 Stice, E. (1994). Review of the evidence for a sociocultural model of bulimia nervosa and an

757 exploration of the mechanism of action. Clinical Psychology Review, 14, 633-661. 
758 Stunkard, A.J., Albaum, J.M. (1981). The accuracy of self-reported weights. The American

759 Journal of Clinical Nutrition, 34(8), 1593-1599. DOI: 10.1093/ajen/34.8.1593.

760 Swami, V.. (2015). Cultural Influences on Body Size Ideals. European Psychologist, 1, 1-8.

761 Thompson, J.K. (2004). The (mis)measurement of body image: Ten strategies to improve 762 assessment for applied and research purposes. Body Image, 1(1), 7-14.

763 Tremblay, L., Lovsin, T., Zecevic, C., Larivière, M. (2011). Perceptions of self in 3-5-year-old 764 children: A preliminary investigation into the early emergence of body dissatisfaction. Body 765 Image, 8(3), 287-292.

766 van Leeuven, Hunt, D.F., Park, J.H. (2015). Is Obesity Stigma Based on Perceptions of 767 Appearance or Character? Theory, Evidence, and Directions for Further Study. Evolutionary 768 Psychology, 13, 1-8.

769 Vani, M., Pila, E., Willson, E., Sabiston, C. (2020). Body-related embarrassment: The 770 overlooked self-conscious emotion. Body Image, 32. 14-23. DOI:

771 10.1016/j.bodyim.2019.10.007.

772 Vartanian, L. R. (2010). Disgust and perceived control in attitudes toward obese people.

773 International Journal of Obesity, 34, 1302-1307.

774 Vartanian, L.R., Shaprow, J.G. (2008). Effects of weight stigma on exercise motivation and 775 behavior: a preliminary investigation among college-aged females. Journal of Health $776 \quad$ Psychology, 13, 131-138.

777 Walsh, O.A., Wadden, T.A, Tronieri, J.S., Chao, A.M., Pearl, R.C. (2018). Weight Bias

778 Internalization Is Negatively Associated With Weight-Related Quality of Life in Persons 779 Seeking Weight Loss. Frontiers in Psychology, 9:2576, 1-5. 
780 Watson, L., Levit, T., Lavack, A.M. (2017). Obesity and Stigmatization at Work. In: S.B.

781 Thomson, G. Grandy (eds.), Stigmas, Work and Organizations (pp.11-34), New York: Palgrave

782 Macmillan.

783 Webb, J.B., Wood-Barcalow, N.L., Tylka, T.L. (2015), Assessing positive body image:

784 Contemporary approaches and future directions. Body Image, 14, 130-145. DOI:

785 10.1016/j.bodyim.2015.03.010.

786 Wertheim, E.H., Paxton, S.J., Tilgner, L. (2004). Test-retest reliability and construct validity of

787 Contour Drawing Rating Scale scores in a sample of early adolescent girls. Body Image, 1(2), 788 199-205.

789 Wojciszke, B. (2011). Psychologia społeczna [Social psychology]. Warszawa: Wydawnictwo 790 Naukowe Scholar.

791 Wojdyło, K., Buczny, J. (2011). Samoregulacja i samokontrola powinnościowe : analiza 792 psychometryczna Skali Rozbieżności Ja (SkRAP) [Self-regulation, self-control, and the ought 793 self. Measuring ought self-discrepancy: A psychometric analysis of the SkRAP], Psychologia 794 Społeczna, 4, 375-390.

795 Williams, O., Annandale, E. (2019). Weight Bias Internalization as an Embodied Process:

796 Understanding How Obesity Stigma Gets Under the Skin. Frontiers in Psychology, 10:953, 1-5.

797 Wu, Y.-K., Berry, D.C. (2017). Impact of weight stigma on physiological and psychological 798 health outcomes for overweight and obese adults: A systematic review. Journal of Advanced 799 Nursing, 74, 1030-1042. DOI: 10.1111/jan.13511 


\section{Table $\mathbf{1}$ (on next page)}

Descriptive statistics of quantitative and qualitative variables in the study 


\section{Table 1:}

2 Descriptive statistics of quantitative and qualitative variables in the study

\begin{tabular}{|c|c|c|c|c|c|}
\hline Quantitative variable & Median & $\begin{array}{l}\text { Lower } \\
\text { quartile }\end{array}$ & $\begin{array}{l}\text { Upper } \\
\text { quartile }\end{array}$ & $\begin{array}{l}\text { Shapiro-Wilk } \\
\text { W }\end{array}$ & $\begin{array}{l}\text { Shapiro-Wilk p- } \\
\text { value }\end{array}$ \\
\hline Age & 22.00 & 21.00 & 24.00 & .895 & $<.001$ \\
\hline Height (m) & 1.67 & 1.62 & 1.70 & .983 & $<.001$ \\
\hline Self-reported body weight $(\mathrm{kg})$ & 60.00 & 55.00 & 69.00 & .814 & $<.001$ \\
\hline BMI & 21.72 & 20.20 & 24.24 & .748 & $<.001$ \\
\hline (1) Actual body image & 5.00 & 4.00 & 7.00 & .956 & $<.001$ \\
\hline (2) Ideal body image & 4.00 & 3.00 & 4.00 & .924 & $<.001$ \\
\hline (3) Reflected body image & 5.00 & 4.00 & 6.00 & .957 & $<.001$ \\
\hline $\begin{array}{l}\text { (4) Ought body image according to } \\
\text { men }\end{array}$ & 4.00 & 3.00 & 5.00 & .910 & $<.001$ \\
\hline $\begin{array}{l}\text { (5) Ought body image according to } \\
\text { women }\end{array}$ & 3.00 & 2.00 & 3.00 & .912 & $<.001$ \\
\hline (1)-(2) Discrepancy & 2.00 & 1.00 & 3.00 & .940 & $<.001$ \\
\hline (1)-(3) Discrepancy & .00 & .00 & 1.00 & .873 & $<.001$ \\
\hline (1)-(4) Discrepancy & 2.00 & 1.00 & 3.00 & .963 & $<.001$ \\
\hline (1)-(5) Discrepancy & 2.50 & 2.00 & 4.00 & .960 & $<.001$ \\
\hline (6) Mental actual self & 81.00 & 69.00 & 92.00 & .972 & $<.001$ \\
\hline (7) Mental reflected self & 87.00 & 74.00 & 98.00 & .975 & $<.001$ \\
\hline (6)-(7) Discrepancy & -6.00 & -12.00 & .00 & .972 & $<.001$ \\
\hline Self-evaluation & 28.00 & 25.00 & 32.00 & .991 & .019 \\
\hline Stereotype of people with obesity & 2.30 & 1.80 & 2.80 & .956 & $<.001$ \\
\hline Qualitative variable & Yes & No & $\%$ Yes & $\%$ No & \\
\hline $\begin{array}{l}\text { Weight norm (BMI according to the } \\
\text { WHO criteria) }\end{array}$ & 298 & 80 & 78.6 & 21.4 & $\begin{array}{l}\text { The group of } \\
\text { participants with } \\
\text { excess weight } \\
\text { includes } 53 \\
\text { participants with } \\
\text { overweight and } 27 \\
\text { participants with } \\
\text { obesity. }\end{array}$ \\
\hline "Do you think you are currently fat?" & 129 & 245 & 34.5 & 65.5 & \\
\hline $\begin{array}{l}\text { "Are you currently ashamed of how } \\
\text { much you weigh? }\end{array}$ & 154 & 220 & 41.2 & 58.8 & \\
\hline Overall weigh-related stigma & 173 & 201 & 46.3 & 53.7 & \\
\hline
\end{tabular}

3 


\section{Table 2 (on next page)}

Body image, self-esteem and mental self-schemas in the groups with different BMI and weight-related stigmatization experiences - Mann-Whitney $U$ tests 
Table 2. Body image, self-esteem and mental self-schemas in the groups with different BMI and weight-related stigmatization

experiences - Mann-Whitney $U$ tests

\begin{tabular}{|c|c|c|c|c|c|c|c|c|}
\hline \multirow[t]{2}{*}{ Variables } & \multicolumn{4}{|c|}{ Median in the BMI group (interquartile range) } & \multicolumn{4}{|c|}{$\begin{array}{l}\text { Median in the weight-related stigmatization } \\
\text { experiences group (interquartile range) }\end{array}$} \\
\hline & Normal & Excess & $\mathrm{p}$ & ES & No & Yes & $\mathrm{p}$ & $\mathrm{ES}$ \\
\hline (1) Actual body image & $5.0(2.0)$ & $8.0(1.0)$ & $<.001$ & -.822 & $5.0(1.0)$ & $6.0(2.0)$ & $<.001$ & -.599 \\
\hline (2) Ideal body image & $4.0(1.0)$ & $4.5(1.5)$ & $<.001$ & -.399 & $4.0(1.0)$ & $4.0(2.0)$ & .264 & -.064 \\
\hline (3) Reflected body image & $4.0(1.0)$ & $7.0(1.5)$ & $<.001$ & -.819 & $4.0(2.0)$ & $6.0(2.0)$ & $<.001$ & -.604 \\
\hline $\begin{array}{l}\text { (4) Ought body image } \\
\text { according to men }\end{array}$ & $4.0(2.0)$ & $4.0(2.0)$ & .787 & -.019 & $4.0(2.0)$ & $3.0(1.0)$ & .072 & .104 \\
\hline $\begin{array}{l}\text { (5) Ought body image } \\
\text { according to women }\end{array}$ & $3.0(1.0)$ & $3.0(1.5)$ & .871 & .011 & $3.0(1.0)$ & $3.0(1.0)$ & .087 & .098 \\
\hline Discrepancy (1)-(2) & $1.0(1.0)$ & $3.0(2.0)$ & $<.001$ & -.635 & $1.0(2.0)$ & $2(1.0)$ & $<.001$ & -.635 \\
\hline Discrepancy (1)-(3) & $0.0(1.0)$ & $0.0(1.0)$ & .003 & .202 & $0.0(1.0)$ & $0(1.0)$ & .008 & .147 \\
\hline Discrepancy (1)-(4) & $1.0(1.0)$ & $4.0(2.0)$ & $<.001$ & -.739 & $1.0(2.0)$ & $3(2.0)$ & $<.001$ & -.612 \\
\hline Discrepancy (1)-(5) & $2.0(2.0)$ & $5.0(2.0)$ & $<.001$ & -.730 & $2.0(2.0)$ & $4(3.0)$ & $<.001$ & -.595 \\
\hline (6) Mental actual self & $82.0(21.0)$ & $76.5(22.5)$ & .002 & .228 & $84.0(18.0)$ & $77.0(23.0)$ & $<.001$ & .242 \\
\hline (7) Mental reflected self & $88.0(22.0)$ & $83.0(22.0)$ & .011 & .184 & $91.0(22.0)$ & $83.0(24.0)$ & .001 & .190 \\
\hline Discrepancy (6)-(7) & $-6.0(12.0)$ & $-6.0(17.0)$ & .874 & -.012 & $-6.0(12.0)$ & $-6.0(15.0)$ & .642 & .028 \\
\hline Self-esteem & $29.0(7.0)$ & $27.0(7.0)$ & .012 & .183 & $30.0(6.0)$ & $26.0(8.0)$ & $<.001$ & .396 \\
\hline
\end{tabular}

3 p-value significant with the Holm-Bonferroni correction were presented in bold; ES - effect size is given by the rank biserial

correlation 


\section{Table 3(on next page)}

Differences between body image aspects and mental self aspects in the groups with different BMI and different weight-related stigmatization experiences - Wilcoxon signedrank tests 
1 Table 3. Differences between body image aspects and mental self aspects in the groups with different BMI and different

\section{2 weight-related stigmatization experiences - Wilcoxon signed-rank tests}

\begin{tabular}{|c|c|c|c|c|}
\hline \multirow[t]{2}{*}{ Compared variables } & \multicolumn{2}{|c|}{$\begin{array}{l}\text { Median in the BMI group (interquartile } \\
\text { range) }\end{array}$} & \multicolumn{2}{|c|}{$\begin{array}{l}\text { Median in the weight-related stigmatization } \\
\text { experiences group (interquartile range) }\end{array}$} \\
\hline & Normal & Excess & No & Yes \\
\hline Actual body image & $5.0(2.0)$ & $8.0(1.0)$ & $5.0(1.0)$ & $6.0(2.0)$ \\
\hline \multirow[t]{3}{*}{ Ideal body image } & $4.0(1.0)$ & $4.5(1.5)$ & $4.0(1.0)$ & $4.0(2.0)$ \\
\hline & $\mathrm{p}<.001$ & $\mathrm{p}<.001$ & $\mathrm{p}<.001$ & $\mathrm{p}<.001$ \\
\hline & $\mathrm{ES}=.926$ & $\mathrm{ES}=1.000$ & $\mathrm{ES}=.905$ & $\mathrm{ES}=.978$ \\
\hline Actual body image & $5.0(2.0)$ & $8.0(1.0)$ & $5.0(1.0)$ & $6.0(2.0)$ \\
\hline \multirow[t]{3}{*}{ Reflected body image } & $4.0(1.0)$ & $7.0(1.5)$ & $4.0(2.0)$ & $6.0(2.0)$ \\
\hline & $\mathrm{p}<.001$ & $\mathrm{p}=.183$ & $\mathrm{p}<.001$ & $\mathrm{p}<.001$ \\
\hline & $\mathrm{ES}=.705$ & $\mathrm{ES}=.220$ & $\mathrm{ES}=.773$ & $\mathrm{ES}=.410$ \\
\hline Actual body image & $5.0(2.0)$ & $8.0(1.0)$ & $5.0(1.0)$ & $6.0(2.0)$ \\
\hline \multirow[t]{3}{*}{ Ought body image according to men } & $4.0(2.0)$ & $4.0(2.0)$ & $4.0(2.0)$ & $3.0(1.0)$ \\
\hline & $\mathrm{p}<.001$ & $\mathrm{p}<.001$ & $\mathrm{p}<.001$ & $\mathrm{p}<.001$ \\
\hline & $\mathrm{ES}=.827$ & $\mathrm{ES}=1.000$ & $\mathrm{ES}=.724$ & $\mathrm{ES}=.986$ \\
\hline Actual body image & $5.0(2.0)$ & $8.0(1.0)$ & $5.0(1.0)$ & $6.0(2.0)$ \\
\hline \multirow[t]{3}{*}{ Ought body image according to women } & $3.0(1.0)$ & $3.0(1.5)$ & $3.0(1.0)$ & $3.0(1.0)$ \\
\hline & $\mathrm{p}<.001$ & $\mathrm{p}<.001$ & $\mathrm{p}<.001$ & $\mathrm{p}<.001$ \\
\hline & $\mathrm{ES}=.971$ & $\mathrm{ES}=1.000$ & $\mathrm{ES}=.960$ & $\mathrm{ES}=.996$ \\
\hline Mental actual self & $82.0(21.0)$ & $76.5 .0(22.5)$ & $84.0(18.0)$ & $77.0(23.0)$ \\
\hline \multirow[t]{3}{*}{ Mental reflected self } & $88.0(22.0)$ & $83.0(22.0)$ & $91.0(22.0)$ & $83.0(24.0)$ \\
\hline & $\mathrm{p}<.001$ & $\mathrm{p}<.001$ & $\mathrm{p}<.001$ & $\mathrm{p}<.001$ \\
\hline & $\mathrm{ES}=-.575$ & $\mathrm{ES}=-.457$ & $\mathrm{ES}=-.585$ & $\mathrm{ES}=-.508$ \\
\hline
\end{tabular}

3 all p-values significant with the Holm-Bonferroni correction; ES - effect size given by the matched rank biserial correlation 